\title{
Economics
}

HEI Working Paper No: 03/2003

\section{An Open Economy New Keynesian Phillips Curve: Evidence from Hong Kong}

\author{
Hans Genberg \\ Graduate Institute of International Studies \\ Laurent L. Pauwels \\ Graduate Institute of International Studies
}

\begin{abstract}
This paper extends the new hybrid Keynesian Phillips curve (NKPC) to the open economy context. We hypothesise that pricing decisions depend on both labour costs and intermediate imported input prices. The results for Hong Kong are consistent with the theory if import prices are given substantial weight in measuring marginal cost, rejecting the labour costs model. We find that forward-looking behaviour is dominant, and that price stickiness is smaller in Hong Kong than in the USA. The results are sensitive to the choice of instruments, and a model using the output gap instead of marginal cost as the forcing variable also performs well.
\end{abstract}

(C) The Authors.

All rights reserved. No part of this paper may be reproduced without the permission of the authors. 


\title{
An Open Economy New Keynesian Phillips Curve: Evidence from Hong Kong
}

(Shortened title: "Open Economy NKPC in Hong Kong")

\author{
Hans Genberg* $*^{*}$ \\ Graduate Institute of International Studies, Geneva, Switzerland \\ Laurent L. Pauwels ${ }^{*}+$ \\ Graduate Institute of International Studies, Geneva, Switzerland
}

This Version: August 2004

\begin{abstract}
This paper extends the new hybrid Keynesian Phillips curve (NKPC) to the open economy context. We hypothesise that pricing decisions depend on both labour costs and intermediate imported input prices. The results for Hong Kong are consistent with the theory if import prices are given substantial weight in measuring marginal cost, rejecting the labour costs model. We find that forward-looking behaviour is dominant, and that price stickiness is smaller in Hong Kong than in the USA. The results are sensitive to the choice of instruments, and a model using the output gap instead of marginal cost as the forcing variable also performs well.
\end{abstract}

Keywords: New Keynesian Phillips curve, inflation dynamics, micro-foundation, open economy macroeconomics, GMM estimation, Hong Kong data.

JEL Classification: E31, E12, F41, N15, C51

\footnotetext{
* Address for Correspondence: Economics Section, Graduate Institute of International Studies, Geneva, Switzerland, 11A Avenue de la Paix, 1202 Geneva. Tel: +41-22-9085900; fax: +41-227333049. Email Address: genberg@hei.unige.ch and pauwels0@hei.unige.ch.

* The paper was prepared in part within the NCCR Finrisk project "Macro Risk, Systemic Risk and International Finance". The NCCR is a research program supported by the Swiss National Science Foundation. Some of the research was carried out while the authors were visitors at the Hong Kong Institute for Monetary Research. We wish to express special thanks to an anonymous referee, IpWing Yu and Stephan Gerlach of the Hong Kong Monetary Authorities, and Michael McAleer of the School of Economics and Commerce, University of Western Australia for helpful suggestions and comments, and for useful discussions: Tommaso Mancini Griffoli and Marwan Elkhoury of the Graduate Institute of International Studies, Geneva, the participants at the $8^{\text {th }}$ Australasian Macroeconomic Workshop, Hong Kong Monetary Authority, Hong Kong; seminar participants at the Research Department, Reserve Bank Australia; School of Economics and Commerce, University of Western Australia, Perth; Research School of Pacific and Asian Studies, Australian National University, Canberra; Department of Economics, Macquarie University, Sydney.
} 


\section{Introduction}

The traditional Phillips curve shows the relationship between the output gap and inflation. The results in the literature have indicated that the model is difficult to reconcile with the empirical facts, as authors have had to model and deal with issues such as inflation persistence, monetary policy shocks and effects of disinflation. In the new literature on inflation dynamics, inflation is related to marginal cost, under the assumption of sticky prices.

Galí and Gertler (1999) propose to measure real marginal cost with real unit labour cost. In their specification they allow for firms to forecast future marginal cost through either forward or backward-looking expectations. The source of rigidity is in wages, which are set in contracts. They find that unit labour costs are statistically significant and qualitatively important, and the forward-looking behaviour captures most firms' behaviour. Both the use of unit labour costs and rational expectations have been subsequently criticised by Roberts (2001), Rudd and Whelan (2001) and Lindé (2001), whose results do not concur with those of Galí and Gertler (1999). They dispute the importance of forward-looking expectations and the ability of the new Phillips curve to account for inflation dynamics adequately. Furthermore, the use of unit labour costs is questioned because it only captures a small part of the economic activity according to Roberts (2001).

In this paper, we apply the theoretical developments of Galí and Gertler (1999) to the small open economy of Hong Kong, which has undergone severe deflation in the last decade. The analysis is conducted using data from the currency board period starting from the first quarter of 1984 until the fourth quarter of 2002. We extend the model of Galí and Gertler (1999) by incorporating open-economy considerations. Specifically, we posit that intermediate imports are important sources of fluctuations in the marginal costs of firms in the short run, an extension pursued by Galí and López-Salido (2000) for Spain. This implies that the proxy for marginal costs in the structural model should be modified to reflect not only labour costs but also the costs of imported intermediate inputs. Our empirical results are consistent with our conjecture.

We use Hansen's (1982) and Hansen and Singleton's (1982) Generalized Method of Moments (GMM) as an instrumental variable technique to identify the structural parameters and to control for potential simultaneity. We investigate the sensitivity of the parameter estimates to the choice of instrument lag length, and use a Model and Moment Selection Criteria (MMSC) for GMM derived by Andrews and $\mathrm{Lu}(1999)$.

Our empirical results can be summarized in four points. First, the marginal cost version of the New Keynesian Phillips curve (NKPC) gives results that are consistent with the theory only if the import prices get a substantial weight (typically larger than one half) in the measure of marginal cost. Second, forward-looking behaviour is important for inflation dynamics in Hong Kong. Third, the output gap performs well in the inflation equation. Lastly, the results are sensitive to the exact choice of instruments used in the GMM estimation thus corroborating some of the criticisms referred to above, and also sensitive to the sample specification. 
The next section describes the new Keynesian Phillips curve and particularly the model by Galí and Gertler (1999). In section 3, the model is extended to allow for the role of imported intermediate inputs and we discuss its microeconomic foundation. In Section 4 we present and analyse the data, in particular in terms of their stationarity properties. Our principal results and specification tests are presented in Section 5. The last section concludes.

\section{The Literature}

\subsection{The New Phillips Curve}

The new Phillips curve builds on earlier works by Taylor (1980) and Calvo (1983), who emphasized sticky nominal wages and prices in a framework of forwardlooking individuals and firms. In the Calvo model, monopolistically competitive firms set prices optimally subjected to a constraint on the frequency of price adjustments that is similar to Taylor's sticky-wage model. Aggregating the optimal price-setting behaviour of individual firms leads to a short-run relationship relating inflation to expected inflation and a measure of total real activity.

Formally the aggregate inflation equation is derived as follows. Each period, firms are faced with the choice of adjusting their prices or keeping them fixed. ${ }^{1} \mathrm{~A}$ fraction $1-\theta$ and $\theta$ will do so respectively, which represents the degree of price stickiness. Since firms are assumed identical, the proportion of firms adjusting at time $t$, will choose the same optimal price $p_{t}^{*}$. The aggregate price level therefore follows:

$$
p_{t}=\theta p_{t-1}+(1-\theta) p_{t}^{*}
$$

and the aggregate inflation rate can be written as:

$$
\pi_{t}=(1-\theta)\left(p_{t}^{*}-p_{t-1}\right)
$$

The optimal price-setting rule in Calvo's framework requires choosing $p_{t}^{*}$ to maximize the present discounted value of profits taking into account the constraint implied by the cost of adjusting prices. Note that if there were no such costs, firm (i) would simply set its price (in log) according to:

$$
p_{t}^{*}(i)=\mu+m c_{t}^{n}(i) \text { for all } t
$$

where $\mu$ is the gross mark-up and $m c_{t}^{n}$ is the log of nominal marginal cost. With the constraint on the adjustment of prices, on the other hand, the profit-maximizing price can be shown to obey:

$$
p_{t}^{*}(i)=\mu+(1-\beta \theta) \sum_{k=0}^{\infty}(\beta \theta)^{k} E_{t}\left[m c_{t+k}^{n}\right]
$$

\footnotetext{
${ }^{1}$ The model used to capture the sluggish adjustment process is a quadratic adjustment cost model due to Rotemberg (1982) first derived for investment in Lucas (1967).
} 
where $\beta$ is the subjective discount factor. In words, when prices are set at time $t$, firms take into account discounted expected future marginal cost, where discounting is done in part by the subjective discount rate and in part by the expected duration or the currently determined price.

Defining $\hat{m} c_{t}$ to be the deviation of the log of real marginal cost from its mean, the new Phillips curve model, relating inflation and marginal cost, takes the form:

$$
\pi_{t}=\delta \hat{m c_{t}}+\beta E_{t}\left\{\pi_{t+1}\right\}+\varepsilon_{t}
$$

where

$$
\delta=\frac{(1-\theta)(1-\beta \theta)}{\theta}
$$

Most of the empirical literature on the new Keynesian Phillips curve has used the output gap to proxy for marginal cost as the driving variable in the inflation equation. Under certain conditions it can be shown that the deviation of marginal cost from its long-run equilibrium value is proportional to the output gap, specifically:

$$
\hat{m c_{t}}=\lambda y_{t}^{*}=\lambda\left(y_{t}-y_{t}^{n}\right)
$$

where $y_{t}^{*}$ is the output gap, $y_{t}$ is the log of output, $y_{t}^{n}$ is the natural level of output, and $\lambda$ is the output elasticity of marginal cost. The transformed model is thus:

$$
\pi_{t}=\phi y_{t}^{*}+\beta E_{t}\left\{\pi_{t+1}\right\}+\varepsilon_{t}
$$

where $\phi=\delta \lambda$. Note that it incorporates a forward-looking component. Inflation varies positively with the output gap, as in the old Phillips curve framework. The implications for the optimal conduct of monetary policy or for the cost of disinflation, however, differ. Optimal monetary policy must be conducted under the assumption of forward-looking agents, who anticipate policies and the future state of monetary variables. Further discussion on optimal monetary policy can be found in Clarida, Galí and Gertler (1999).

\subsection{Hybrid New Keynesian Phillips Curve}

Fuhrer's (1997) results indicate that the new Keynesian sticky-price model fails due to the fact that part of the market uses a univariate rule to predict next period's price level, while the rest forecast inflation using method consistent with full rationality.

Departing from equation (1), Galí and Gertler (1999) allowed for a fraction $(1-\kappa)$ of the firms to set their expectation in a forward-looking way and a proportion 
$\kappa$ of the firms to set expectations in a backward-looking fashion. The new index of prices set at $t$ is given by:

$$
p_{t}^{*}=(1-\kappa) p_{t}^{f}+\kappa p_{t}^{b}
$$

where $p_{t}^{f}$ is the price set by a forward-looking firm and $p_{t}^{b}$ refers to the prices set in a backward-looking fashion. A fraction $(1-\kappa)$ of forward-looking agents set prices in the following manner:

$$
p_{t}^{f}=\mu+(1-\beta \theta) \sum_{k=0}^{\infty}(\beta \theta)^{i} E_{t}\left[m c_{t+k}^{n}\right]
$$

The backward-looking price rule can be expressed as:

$$
p_{t}^{b}=p_{t-1}^{*}+\pi_{t-1}
$$

where $p_{t-1}^{*}$ is a set of average prices (also partly determined by forward-looking price makers in the past), when these have been adjusted and corrected for inflation $\pi_{t-1}$. Combining equation (1), (8), (9) and (10):

$$
\pi_{t}=\delta^{h} \hat{m} c_{t}+\omega^{f} E_{t}\left\{\pi_{t+1}\right\}+\omega^{b} \pi_{t-1}+\varepsilon_{t}
$$

where the error term $\varepsilon_{t}$ indicates potential measurement errors or shocks to the desired mark-up as in Galí, Gertler and López-Salido (2003). In estimating equation (11), Galí and Gertler (1999) use real labour income share as a marginal cost measure instead of the output gap. The coefficients of equation (11) can be further identified:

$$
\begin{aligned}
& \delta \equiv(1-\kappa)(1-\theta)(1-\beta \theta) \psi^{-1} \\
& \omega^{f} \equiv \beta \theta \psi^{-1} \\
& \omega^{b} \equiv \kappa \psi^{-1} \\
& \text { and } \\
& \psi \equiv \theta+\kappa[1-\theta(1-\beta)]
\end{aligned}
$$

\subsection{Gali \& Gertler's (1999) Results}

Galí and Gertler's (1999) approach yields four main results: (1) statistically and quantitatively significant real marginal costs as determinants of inflation, (2) forward-looking rule accounts for the majority of the firms' behaviour ( $\omega^{f}$ is significantly larger than $\omega^{b}$ ), (3) backward-looking behaviour is statistically but not quantitatively important, and (4) the new Keynesian Phillips curve provides a good and robust estimation of the actual inflation dynamics. 


\subsection{Critiques of the Hybrid NKPC}

Roberts' (2001) critique of the hybrid model proposed by Galí and Gertler (1999) is that their results hinge on the use of average labour productivity as a measure of marginal labour productivity, which in itself is very pro-cyclical. Roberts (2001) argues that the results obtained when using the real labour cost variable can be interpreted as capturing a "narrower phenomena". The traditional Phillips curve, however, is meant to capture the effects of economic activity on all dimension of marginal cost. Furthermore, his findings indicate the models of inflation fit better when they include lags of inflation, thereby rejecting the assumption of pure rational expectation.

Rudd and Whelan (2001) and Lindé (2001) present evidence that the new hybrid Keynesian Phillips curve is not adequate to approximate inflation dynamics empirically. Their findings indicate that the model using either the output gap or the labour share fail to describe the reduced-form inflation equation. A response to those criticisms is formed in Galí, Gertler and López-Salido (2003). However, lags of inflation in the reduced-form new Phillips curve are used to proxy expected future values of the driving variable, which is contradicted by the small role inflation plays in forecasting future values of labour share or output gap. Fuhrer and Moore (1995) argue that a staggered contracting model of the new Keynesian Phillips curve cannot explain the persistence in inflation observed in the data. Rudd and Whelan (2001) conclude that the Phillips curve models do not explain the role of lagged inflation, which should imply necessarily that agents formulate their expectations in a backward-looking manner.

\section{Open Economy Hybrid NKPC}

Although Galí and Gertler's model has captured inflation dynamics in the US and EU fairly well, it does not leave any room for external influences on domestic inflation except through the wage rate that in turn influences marginal cost. Yet in open economies it is often believed that external inflation may have a more direct influence. In this section we model this influence by extending the marginal cost measure in light of the results in Genberg and Pauwels (2003). We argue that price setting in a highly open economy is likely to be influenced by foreign prices through intermediate inputs, as formulated in Galí and López-Salido (2000) for their Spanish inflation analysis. Gagnon and Khan (2001) have attempted to modify the marginal cost measure through the use of different types of production functions. Open economy considerations also have been taken into account by various authors in various ways, as Galí and Monacelli (2000) and Balakrishnan and López-Salido (2002). This literature introduces open economy components in the NKPC by explicitly integrating exchange rate and intermediate imported input considerations directly in the structural equations underlying the reduced form econometric model. We propose a weighted average marginal cost featuring intermediate imported input costs as well as labour input costs to account for open economy influences on inflation. 


\subsection{Modelling Marginal Cost}

The marginal cost measure featured in equation (11) is derived from a simple cost minimisation procedure. Generally, the cost minimising problem for $n$ inputs can be written as:

$$
\underset{C_{t}}{\operatorname{Min}} C_{t}=\sum_{i=1}^{n} w_{i, t} X_{i, t}
$$

where $w_{i, t}$ is the $i^{\text {th }}$ input price valued at time $t$ and $X_{i, t}$ is the $i^{\text {th }}$ input at time $t$, subject to the production function:

$$
Y_{t}=A \prod_{i=1}^{n} X_{i, t}^{\alpha_{i}}
$$

where $Y_{t}=f\left(X_{i, t} ; \alpha_{i}\right)$ is output as a function of inputs and their shares $\alpha_{i}$ and $A$ is technology. We assume that $\sum_{i=1}^{n} \alpha_{i}=1$, for a Cobb-Douglas production function. The first order conditions yield the following shadow price in real terms:

$$
\lambda_{t}^{\text {real }}=\frac{w_{i, t} X_{i, t}}{\alpha_{i} P_{t} Y_{t}}, \text { for all } i
$$

where $P_{t}$ is the price level. We can define the log deviation of multi-input-marginalcost from its steady-state value by

$$
\begin{aligned}
& \hat{m i m c_{t}}=\sum_{i=1}^{n} \xi_{i}\left(s_{i, t}-s_{i, t}^{*}\right) \\
& \text { or } \\
& \hat{m i m c_{t}}=\sum_{i=1}^{n} \xi_{i}\left(\hat{s}_{i, t}\right)
\end{aligned}
$$

where $s_{i, t}=\ln \left(\frac{w_{i, t} X_{i, t}}{P_{t} Y_{t}}\right), s_{i, t}^{*}$ is the steady-state value of the $i^{\text {th }}$ input income share and restricting $\sum_{i=1}^{n} \xi_{i}=1$. One needs to distinguish between the two parameters, $\alpha$ and $\xi$. The former refers to the relative shares of inputs in the production function, whereas the latter is intended to capture the importance of different components of marginal cost in the short run dynamics of inflation. There is no a priori reason why these two sets of parameters should be equal. 


\subsection{Modelling Unit Labour Cost}

In this section we elaborate on the construction of the marginal cost measure introduced both in Sbordone (1998) and Galí and Gertler (1999). They set up the following Cobb-Douglas technology:

$$
Y_{t}=A L_{t}^{\alpha}
$$

where $A$ is technology and $L_{t}$ labour. Cost minimisation implies that real marginal cost is given by

$$
m c_{t}=\frac{W_{t}}{P_{t}} \cdot \frac{1}{\alpha \frac{Y_{t}}{L_{t}}} \text { or } m c_{t}=\frac{s_{t}^{L}}{\alpha}
$$

where $s_{t}^{L}$ represents labour's share in the value of total output.

\subsection{Open Economy Marginal Cost}

In the case of two inputs, $Y_{t}=\left(A L_{t}\right)^{\alpha} M_{t}^{1-\alpha}$, where $A L_{t}$ is augmented labour and $M_{t}$ is the import component, the minimisation yields:

$$
\lambda_{t}=\frac{w_{t} L_{t}}{\alpha Y_{t}}=\frac{P_{t}^{i m} M_{t}}{(1-\alpha) Y_{t}}
$$

where $w_{t}$ is the nominal wage and $P_{t}^{i m}$ is the intermediate import price. As before we can define a log deviation from mean open economy marginal cost index ( $\hat{o} c)$ by:

$$
o \hat{m} c_{t}=\xi \hat{s}_{t}^{L}+(1-\xi) \hat{s}_{t}^{i m}
$$

where $\hat{s}_{t}^{i m}$ is the log deviation of real intermediate imported input cost from steady state. The parameter $\xi$ is between 0 and 1 , and needs to be calibrated. This weighted cost measure nests Galí and Gertler's (1999) labour cost based marginal cost. The final expression for the rate of inflation is:

$$
\pi_{t}=\delta^{h} o \hat{m} c_{t}+\omega^{f} E_{t}\left\{\pi_{t+1}\right\}+\omega^{b} \pi_{t-1}+\varepsilon_{t}
$$

with the relationship between the coefficients and the structural parameters as defined above in (12).

\section{Data, Tests and Instruments}

The sample used for the regressions spans from the first quarter of 1984 until the fourth quarter of 2002, corresponding to the Currency Board years in Hong Kong. 


\subsection{Regressand and Regressors}

We measure inflation $\left(\pi_{t}\right)$ using the log difference of the GDP deflator. When testing for unit roots, the Augmented Dicky-Fuller test (ADF) does not reject the null of a unit root, whereas the Phillips-Perron test (PP) does. We investigate also the presence of a once-over change in its mean, a possibility we shall return to.

The forcing variable (the marginal cost of production index) is measured by combining real unit labour cost, following the initial Galí and Gertler (1999) application and real import cost as explained in the previous section. Their log deviations from mean, $\hat{s}_{t}^{L}$ and $\hat{s}_{t}^{i m}$, are both non-stationary at the $5 \%$ level of significance but their linear combination, ômc (for $\xi=0.5$ ), is stationary. ${ }^{2}$ For other values of $\xi$, ômc may not be stationary, but the stationarity tests tend to be biased towards the non-rejection of the null. This empirical problem of non-stationarity of marginal cost is not explicitly investigated in Galí and Gertler (1999) or in Galí, Gertler and López-Salido (2001). Potential output was estimated using the HodrickPrescott (HP) filter with a smoothing parameter of 1600, and the output gap $\left(y_{t}^{*}\right)$ was constructed as the log difference between actual and potential output. This measure is also stationary (table 1).

In Figures 1-4, each of the three individual forcing variables $\left(\hat{s}_{t}^{L}, \hat{s}_{t}^{i m}\right.$, and $\left.y_{t}^{*}\right)$ and one combined 'open economy marginal cost' ( $\hat{m} c)$ measure are plotted together with our inflation variable. It is interesting to note that the output gap and the open economy marginal cost measures both appear to track inflation better than the closed economy marginal cost index based only on the cost of labour.

\subsection{The Instruments}

The main difficulty in using an instrumental variable estimation technique such as GMM is to find appropriate instruments and to choose their lag structure. In our model the instrumental variables are needed for $E_{t}\left\{\pi_{t+1}\right\}$ which is clearly endogenous, and possibly also for the current values of the forcing variables, the output gap and the marginal cost. Valid instruments are therefore exogenous variables and lags of the endogenous variables in the model.

In principle there is no limit as to the number of instruments to include, but one should be careful in including too many in small sample as it could over-fit the equation and yield biased results. On the other hand more instruments and lags help capture the movements in the variables of interest. Tauchen (1986), in his MonteCarlo simulation of GMM regression, found that the most credence should be placed on estimates obtained with small instrument sets, because the confidence intervals are

\footnotetext{
${ }^{2}$ The combined open economy marginal cost measure uses equal weights on the wage- and importprice components as an illustration. In our empirical work we estimate the weights using a calibration procedure.
} 
more reliable. More discussion on instrumental sets can be found in Galland and Tauchen (1996) and Bates and Halbert (1988).

In our case the list of instruments are lagged values of the inflation rate $\left(\pi_{t}\right)$, import inflation $\left(\pi_{t}^{i m}\right)$ and world CPI inflation $\left(\Delta_{1} c p i_{t}^{w}\right)$ both illustrated in figure 5 and 6 (see appendix A2 for definition). We do not include nominal wage inflation $\left(\Delta_{1} w_{t}^{\text {nominal }}\right)$, as the measure is potentially non-stationary.

\subsection{Structural Breaks}

The findings that the GDP deflator and nominal wages are integrated of order two is puzzling. It is likely that the events of the Asian financial crisis around the third quarter of 1997 generated a structural break in the path of the variables as suggested from figure 7 and 8. It is known in the literature that the various Dicky-Fuller and Phillips-Perron test statistics are biased toward the non-rejection of a unit root when there is a structural change in the data as noted particularly by Perron (1989).

When the Perron (1989) test is conducted, the test statistic for inflation rejects the null of a unit root against the alternative hypothesis of a one-time change in its mean on the third quarter of 1997 (table 2). Two scenarios are possible: one in which the mean of inflation changes again, either by returning to its prior break level of fluctuation (transforming the one-time change in mean into a "crash" period) or by changing mean again (higher, or further decline). It could also be, however, that the unit root in the inflation rate is caught due to the persistent deflation for the last decade, and that the Asian financial crisis effect is only a short run shock.

We investigate the structure of wage inflation for a structural change due to the Asian financial crisis. The Perron (1989) test does not reject the null of a unit root for nominal wages inflation. It is worth noting from looking at the plot that the trend in nominal wage seems to change three times, which could be a reason for the difficulties encountered.

\section{Empirical Results}

\subsection{Regressions}

We estimate two versions of the hybrid new Phillips curve, first with the traditional output gap as the forcing variable and then using $o \hat{m} c$ as presented in (16), which can be re-written as:

$$
o \hat{m} c_{t}=\hat{s}_{t}^{i m}+\xi\left(\hat{s}_{t}^{L}-\hat{s}_{t}^{i m}\right)
$$

The latter specification involves calibration of $\xi$ as adjustment parameter when marginal cost is deviating from equilibrium. $\xi$ is calibrated between 0 and 1 , with a 
step of 0.05 . Corresponding to the two specifications of the model, the orthogonality conditions can be written as follows: ${ }^{3}$

$$
\begin{aligned}
& E_{t}\left[\left(\pi_{t}-\phi y_{t}^{*}-\omega^{f} E_{t}\left\{\pi_{t+1}\right\}-\left(1-\omega^{f}\right) \pi_{t-1}\right) \mathbf{z}_{\mathbf{t}}^{n, i}\right] \\
& E_{t}\left[\left(\pi_{t}-\delta^{h}\left(\hat{s}_{t}^{i m}+\xi\left(\hat{s}_{t}^{L}-\hat{s}_{t}^{i m}\right)\right)-\omega^{f} E_{t}\left\{\pi_{t+1}\right\}-\left(1-\omega^{f}\right) \pi_{t-1}\right) \mathbf{z}_{\mathbf{t}}^{n, i}\right]
\end{aligned}
$$

where $\mathbf{z}_{\mathbf{t}}^{n, i}$ refers to specific instrument sets as defined below. In all our specifications we assume that $\beta=1$ so that $\omega^{f}+\omega^{b}=1$. As in equation (6) and (7), we define $\phi=\delta^{h} \lambda$, where the output elasticity of marginal cost $\lambda$ is set to $l$ when identifying the structural parameters. The instrument sets are the same for both orthogonality specifications. The regressions are run independently using initially the instrument set including lags of inflation rate, and current and lag values of both world CPI inflation and import price inflation. Specifically, there are four instrument specifications:

$\mathbf{z}_{\mathbf{t}}^{1, i}=\left\{\pi_{t-1 \rightarrow t-i}, \Delta_{1} c p i_{t}^{\text {world }}, \pi_{t}^{i m}\right\}$,

$\mathbf{z}_{\mathbf{t}}^{2, i}=\left\{\pi_{t-1 \rightarrow t-i}, \Delta_{1} c p i_{t}^{w}, \ldots, \Delta_{1} c p i_{t-2}^{w}, \pi_{t}^{i m}, \ldots, \pi_{t-2}^{i m}\right\}$,

$\mathbf{z}_{\mathbf{t}}^{3, i}=\left\{\pi_{t-1 \rightarrow t-i}, \Delta_{1} c p i_{t}^{w}, \pi_{t}^{i m}, y_{t-1}^{*}\right\}$ and

$\mathbf{z}_{\mathbf{t}}^{4, i}=\left\{\pi_{t-1 \rightarrow t-i}, \Delta_{1} c p i_{t}^{w}, \ldots, \Delta_{1} c p i_{t-2}^{w}, \pi_{t}^{i m}, \ldots, \pi_{t-2}^{i m}, y_{t-1}^{*}, \ldots, y_{t-2}^{*}\right\}$.

$i=2, \ldots, 6$

$\mathbf{z}_{\mathbf{t}}^{3, i}$ and $\mathbf{z}_{\mathbf{t}}^{4, i}$ include also one and two lags of the output gap respectively. We allow for lags of the inflation rate to vary independently $\left(\pi_{t-1 \rightarrow t-i}\right)$ from $t-1$ to $t$-6 within all four instrumental specifications. For example, $\mathbf{z}_{\mathbf{t}}^{1,3}$ is the instrument set containing: $\left\{\pi_{t-1}, \ldots, \pi_{t-3}, \Delta_{1} c p i_{t}^{\text {world }}, \pi_{t}^{i m}\right\}$. Lastly, we perform robustness test by reducing the sample to 1984 Q1 - 1997 Q2.

\subsection{Results}

a. The output gap as the forcing variable

When the new Keynesian Phillips curve is specified with the output gap as a driving variable, the degree of stickiness in price varies from 2.6 to 3.1 quarters. The extend to which the typical firm is forward-looking is less precisely determined and varies between 32 to 98 percent depending on the instrument set as shown in table 3 . $^{4}$ Galí and Gertler (1999) find that using the output gap as a measure of marginal costs yields results that are inconsistent with the underlying theory. Note that we also obtain such inconsistent results (not shown in the table) in some specification depending on the number of lags of inflation included in the instrument set.

\footnotetext{
${ }^{3}$ Note that the Galí and Gertler (1999) specification is nested in our second specification, because when $\xi=1$ the marginal cost measure only contains labour costs.

${ }^{4}$ These inferences about the structural parameters are made on the assumption that the elasticity of marginal cost with respect to the output gap is unity.
} 


\section{b. Open economy marginal cost}

The degree of price stickiness varies from 2.4 to 6.6 quarters. This is less than in the United States where Galí and Gertler (1999) found the degree of stickiness to be 4 quarters on average. It is also less than the 5 quarters that Galí, Gertler and LópezSalido (2001) found for the European Union. One can expect the price adjustment in a highly open economy such as Hong Kong to be faster than elsewhere. Note that including the lags of the output gap as an instrument tend to increase the length of price adjustment. Between 46 and 94 percent of the firms adjust their price in a forward-looking fashion corroborating what was obtained using the output gap (table 4).

An important aspect of the results is that consistency between theory and the empirical estimates depends on the size of $\xi$, the share of labour costs in overall marginal cost. It is only when this share is relatively small, less than 0.5 in most cases, that the coefficient on marginal cost has the expected positive sign and is statistically significant. In other words it appears that in Hong Kong imported input costs are more important than labour costs in the price determination process.

\section{c. Results for the pre-crisis sample}

The overall performance of the open economy marginal cost model is not affected when the sample is reduced to exclude the post 1997 Q2 period. The quarterly adjustment of prices is on average faster than in the full sample, and the range of forward-looking behaviour is narrower, between 77 and 98 percent (table 5). Furthermore, the weight on import input costs is again greater than 0.5. As in the full sample, there is indication of some sensitivity of these estimates to the choice of the instrument set, particularly the number of lags of inflation.

The results with the output gap are consistent with the full sample results with a 2.6 quarter price adjustment delay, faster than the open economy marginal cost specification, and 70 percent forward-looking firms.

\section{Conclusion}

We have tested the new Keynesian Phillips curve in the context of a small open economy, using the output gap and a specification of marginal cost including unit labour costs and import input costs. We find that the model performs better in Hong Kong when marginal cost is specified to include a larger share on import input costs. The number of lags of the inflation rate as an instrument is important in determining the statistical significance of the coefficient on marginal cost or the output gap. Both the specification using the output gap and that using open economy marginal cost yield similar estimates, although the specification including the open economy marginal cost indicates a slightly higher degree of price stickiness. 


\section{Appendix}

\section{A1. Model and Moment selection}

Model and Moment selection in GMM modelling is an important current area of research in econometric theory. Andrews and Lu (1999) have adapted the familiar Akaike (AIC), Schwartz Bayesian (BIC) and Hanan-Quinn (HQIC) information criterion for GMM. The so-called Model and Moment Selection Criterion (MMSC) makes use of the $J$ statistic for testing overidentifying restrictions to which are subtracted different penalty terms in same manner as with AIC, SBC and HQIC. Andrews and Lu (1999) show that these terms are the proper analogue of the AIC, BIC and HQIC model selection criteria as asymptotically it makes the trade-off between model fit and the number of parameters. The respective tests present in the following way:

MMSC - BIC: $\operatorname{MMSC}_{\text {BIC }}, n=J_{n}(k, r)-(|r|-|k|) \ln n$

MMSC-AIC: $\operatorname{MMSC}_{A I C}, n=J_{n}(k, r)-2(|r|-|k|)$

MMSC - HQIC: MMSC $_{\text {HQIC }}, n=J_{n}(k, r)-T(|r|-|k|) \ln \ln n$

where $J_{n}(k, r)$ is the $J$-statistic depending on $k$ and $r$, vectors selecting respectively some parameters and some moment conditions, but not necessarily all of them. Furthermore, $|r|$ and $|k|$ are the number of parameters and moment conditions selected by the $J$-statistic. Lastly, $n$ is the number of observations and $T>2$. In this study, we let the $k$ and $r$ to be all the parameters and all the moment conditions.

Andrews and $\mathrm{Lu}(1999)$ test the information criteria for panel data GMM estimation, whereas here they are used in the time-series context, and for the Phillips curve. We report the AIC criterion in the results tables. As the lag length of the instruments change and the number of instruments increase the three criteria tend to increase steadily together. ${ }^{5}$ These information criteria do not seem to be reliable in selecting an appropriate specification in our time-series Phillips curve models.

\footnotetext{
${ }^{5}$ This comment applies to the BIC and HQC criteria
} 


\section{A2. Data definitions and sources.}

Data

The sample period spans from the first quarter of 1984 to the first quarter of 2003. Most of the data was retrieved from the Hong Kong Monetary Authority internal database and some from the CEIC database to which the Hong Kong Institute for Monetary Research has subscribed.

\section{Seasonal Adjustment}

All the variables used as such and to generate other measures have been adjusted for seasonality using the X-11 method (multiplicative) created by the U.S. Bureau of Census. The procedure was performed on nominal and real GDP, nominal wages, average working hours, world CPI, imports and import prices.

\section{Natural Logarithm}

All variables are measured in natural logarithm

1. GDP Deflator

The deflator is constructed dividing nominal by real GDP (at 1990 prices), both seasonally adjusted before hand.

2. Nominal Wages

Nominal wages are based on a seasonally adjusted nominal wage index (September $1992=100)$.

\section{Import Prices}

Import prices are based on the seasonally adjusted quarterly unit value index of imports $(1990=100)$.

\section{Output gap}

The output gap $y_{t}^{*},\left(y-y^{n}\right)$, is created using a Hodrick-Prescott filter (with a smoothing coefficient of 1600) on seasonally adjusted real GDP to generate potential output and then subtracted from seasonally adjusted real GDP.

\section{Labour Force (Hours Worked)}

Average hours of work per employed person in number of hours.

6. Imports

Value of Imports into Hong Kong, SAR in millions of Hong Kong dollars.

\section{World CPI}

World prices are derived from the 14 largest trading partners to the Hong Kong $(1990=100)$ and adjusted in HKD using the nominal effective exchange rate index (NEERI, November 83=100). 


\section{References}

Andrews, D. K., Lu, B (2001) "Consistent Model and Moment Selection Criteria for GMM Estimation with Applications to Dynamic Panel Models," Journal of Econometrics 101, 123-164

Balakrishnan, R., López-Salido, J. D. (2002) "Understanding UK Inflation: the Role of Openness," Working Paper No. 164, Bank of England.

Bates, C., Halbert, W. (1988) "Efficient Instrumental Variables Estimation of Systems of Implicit Heterogeneous Non-linear Dynamic Equation with Nonspherical Errors," in William A. Barnett, Ernst R. Berndt, and Halbert White (Eds.), Dynamic Econometric Modeling, Cambridge: Cambridge University Press.

Calvo, G. A. (1983) "Staggered Prices in a Utility Maximising Framework," Journal of Monetary Economics 12, 383-398.

Clarida, R., Galí, J., Gertler, M. (1999) "The Science of Monetary Policy: A New Keynesian Perspective," Journal of Economic Literature 37 (2), 1661-1707.

Fuhrer, J., Moore, G. R. (1995) "Inflation Persistence," Quarterly Journal of Economics 110, 127-159.

Fuhrer, J. (1997) "The (Un)Importance of Forward-Looking Behavior in Price Specifications," Journal of Money, Credit and Banking 29, 338-350.

Gagnon, E., Khan, H. (2001) "New Phillips Curve with Alternative Marginal Cost Measures for Canada, the United States, and the Euro Area," Working Paper 2001-25, Bank of Canada.

Galland, A, R., Tauchen, G. (1996) "Which Moment to Match?," Econometric Theory $12,657-681$.

Galí, J., Gertler, M. (1999) "Inflation dynamics: A Structural Econometric Analysis," Journal of Monetary Economics 44, 195-222.

Galí, J., Gertler, M., Lopez-Salido, D. (2001) "European Inflation Dynamics," European Economic Review 45 (7), 1237-1270.

Galí, J., Gertler, M., López-Salido, J. D (2003) "Robustness of the Estimates of the Hybrid New Keynesian Phillips Curve," CEPR Conference, Berlin, June 5 - 7.

Galí, J., López-Salido, J. D. (2000) "A New Phillips Curve for Spain," Banco de Espana, mimeo. Paper prepared for the XIII Simposio de Moneda y Crédito on'El Análisis Económico frente a los problemas de la Sociedad Moderna', Madrid, November.

Gali, J., Monacelli, T. (2000) "Monetary Policy and Exchange Rate Volatility in a Small Open Economy," Working Paper No. 438, Boston College. 
Genberg, H., Pauwels, L. (2003) "Inflation in Hong Kong, SAR - In Search for a Transmission Mechanism," Working Paper No.1, HKIMR.

Hansen, L. (1982) "Large Sample Properties of Generalized Method of Moments Estimators," Econometrica 50, 1029-1054.

Hansen, L., Singleton, K. (1982) "Generalized Instrumental Variables Estimation of Nonlinear Rational Expectations Models," Econometrica 50, 1269-1286.

Lindé, J. (2000) "Estimating New-Keynesian Phillips Curves: A Full Information Maximum Likelihood Approach," Working Paper No.129, Sveriges Riksbank.

Lucas, R. E. (1967) "Adjustment Costs and the Theory of Supply," Journal of Economy 75, 321-334.

Newey, W., West, K. (1987) "A Simple Positive Semi-Definite, Heteroskedasticity and Autocorrelation Consistent Covariance Matrix," Econometrica 55, 703-708.

Pauwles, L. (2002) Inflation Dynamics in Hong Kong, SAR: The New Keynesian Phillips Curve in a Small Open Economy and the Use of GMM, Mémoire de D.E.S, Graduate Institute of International Studies, Geneva, October.

Perron, P. (1989) "The Great Crash, the Oil Shock and the Unit Root Hypothesis," Econometrica 57, 1361-1402.

Roberts, J. M. (2001) "How Well Does the New Keynesian Sticky-Price Model Fit the Data?" Working Papers, Federal Reserve Board.

Rotemberg, J. J. (1982) "Sticky Prices in the United States," Journal of Political Economy 60, 1187-1211.

Rudd, J., Whelan, K. (2001) "New Tests of the New-Keynesian Phillips Curve," Working Papers, Federal Reserve Board, Division of Research and Statistics..

Sbordone, A. M. (2002) "Prices and Unit Labor Costs: A New Test of Price Stickiness," Journal of Monetary Economics 49 (2), 265-292.

Tauchen, G. (1986) "Statistical Properties of Generalized Method-of-Moments Estimators of Structural Parameters Obtained From Financial Market Data," Journal of Business \& Economic Statistics 4, 397-416.

Taylor, J. B. (1980) "Aggregate Dynamics and Staggered Contracts," Journal of Political Economy 88, 1-23. 


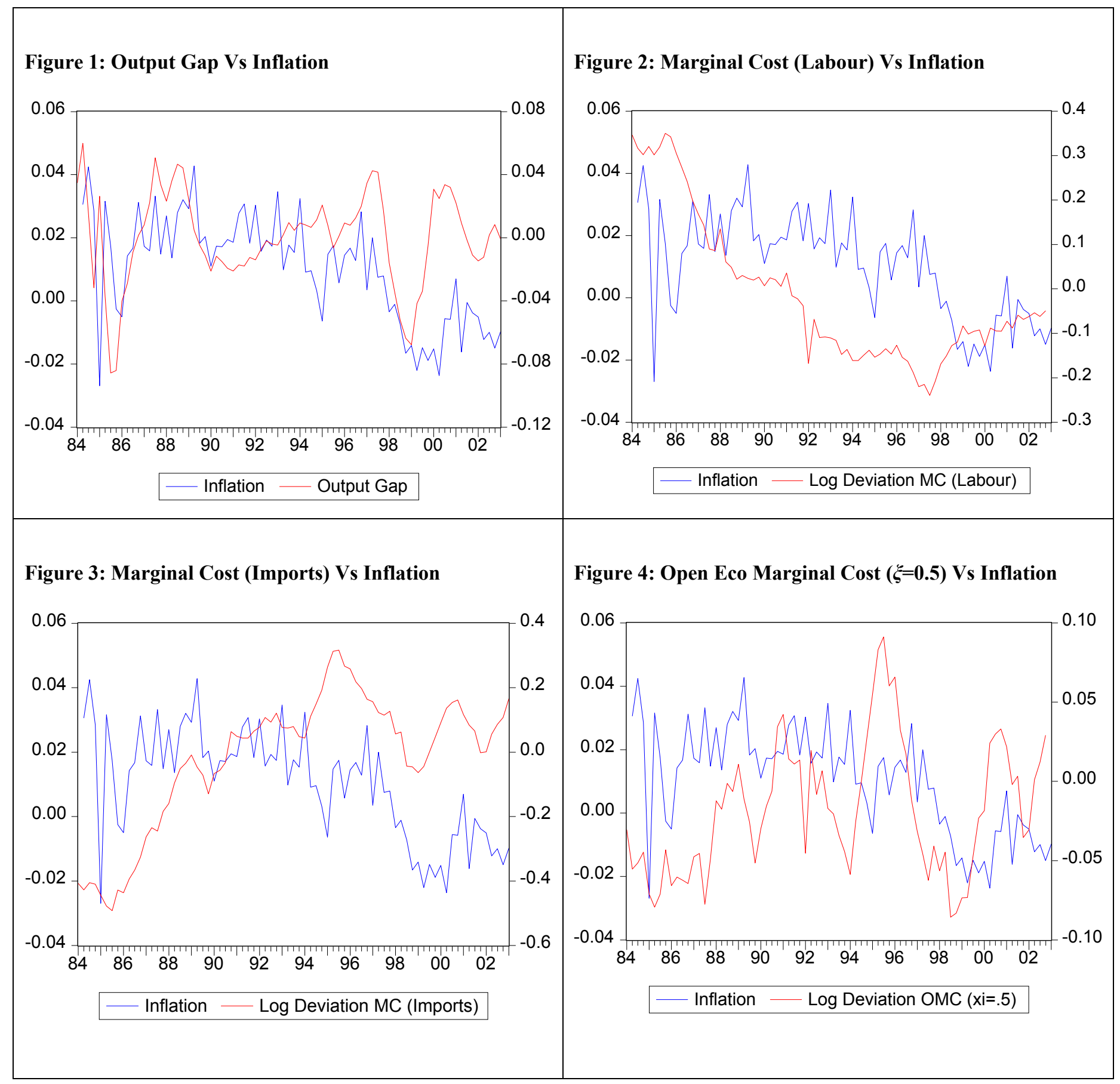




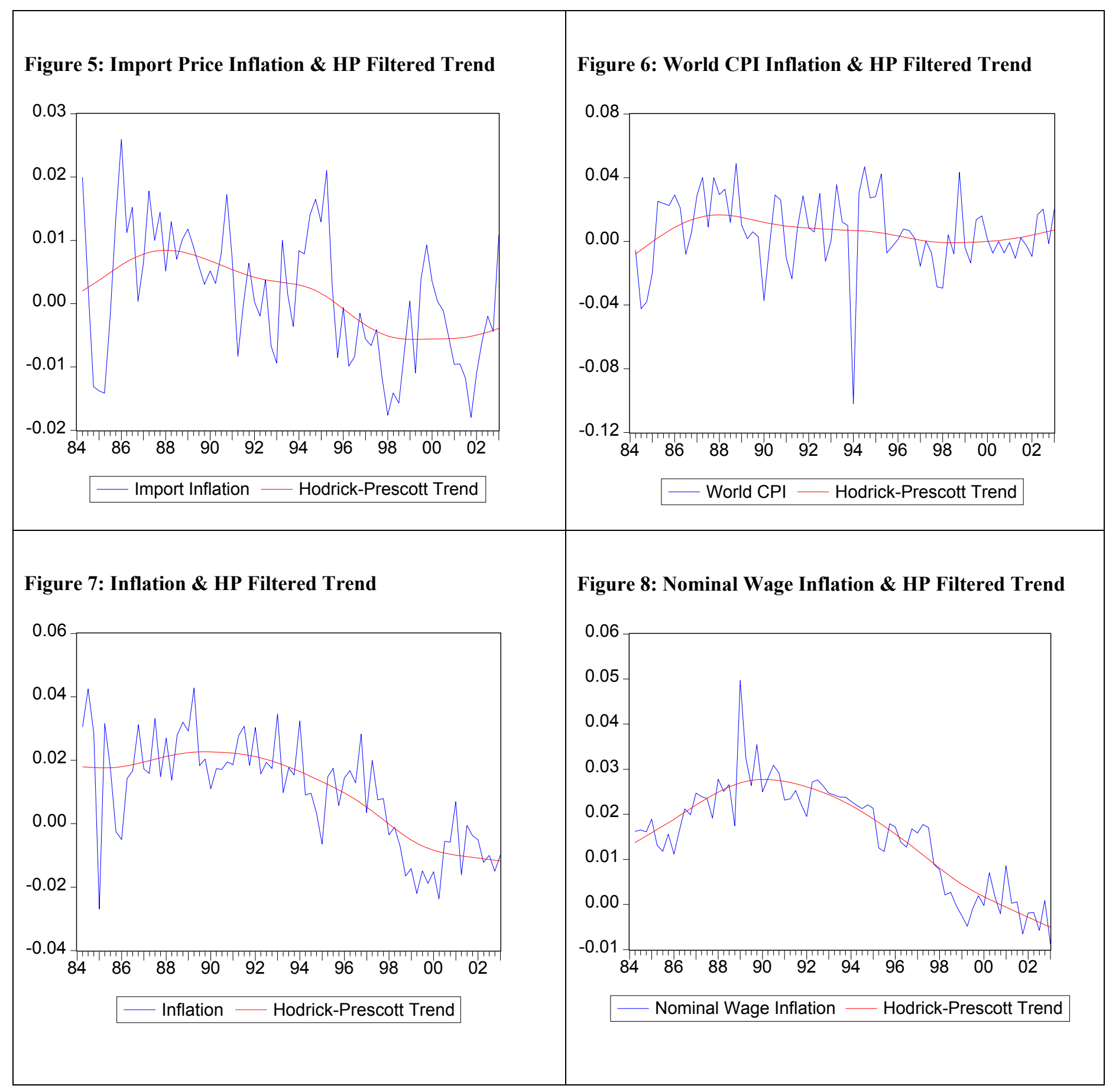


Table 1: ADF \& Phillips-Perron Test Results

\begin{tabular}{c|ccc}
\hline Variables & ADF & Phillips-Perron & Unit Root \\
\hline$\pi_{t}$ & -1.084 & $-4.258^{* * *}$ & Uncertain \\
$\hat{s}_{t}^{L}$ & -2.477 & -2.465 & Yes \\
$\hat{s}_{t}^{i m}$ & $-2.774^{*}$ & -1.716 & Yes \\
ômc $(\xi=.5)$ & $-3.057 * *$ & $-2.700^{*}$ & No \\
$w_{t}^{n o \min a l}$ & -0.203 & 2.161 & Yes \\
$\Delta_{1} w_{t}^{n o \min a l}$ & -0.128 & -1.251 & Yes \\
$c p i_{t}^{w}$ & -2.208 & -1.399 & Yes \\
$\Delta_{1} c p i_{t}^{w}$ & $-6.801 * * *$ & $-6.709^{* * *}$ & No \\
$p_{t}^{i m}$ & -1.184 & -0.424 & Yes \\
$\pi_{t}^{i m}$ & $-4.096^{* * *}$ & $-4.314^{* * *}$ & No \\
$y_{t}^{*}$ & $-3.488^{* *}$ & $-3.514 * *$ & No \\
\hline
\end{tabular}

Notes: (1) A trend and a constant are included when testing the log level and a constant only when testing the difference. (2)We select the "optimal" lag sequence for the ADF test (maximum 6 lags) using four criteria: Akaike (AIC), Schwartz (BIC), Hannan-Quinn (HQIC) and the Log-Likelihood (LL) criteria. (3)*/**/*** represent $10 \% / 5 \% / 1 \%$ level of significance.

Table 2: Perron (1989) Test Results

\begin{tabular}{c|cc}
\hline Variables & Test Value & Unit Root \\
\hline$\pi_{t}$ & -4.321 & No \\
$\Delta_{1} w_{t}^{n o \min a l}$ & -2.509 & Yes \\
\hline
\end{tabular}

Notes: (1) The Perron (1989) critical value is -3.80 at the $5 \%$ significance level. (2) $\mathrm{H}_{0}$ : unit root; $\mathrm{H}_{\mathrm{a}}$ : one-time change in the mean. (3) We correct for serial correlation and use the same selection procedure as with the ADF tests. 


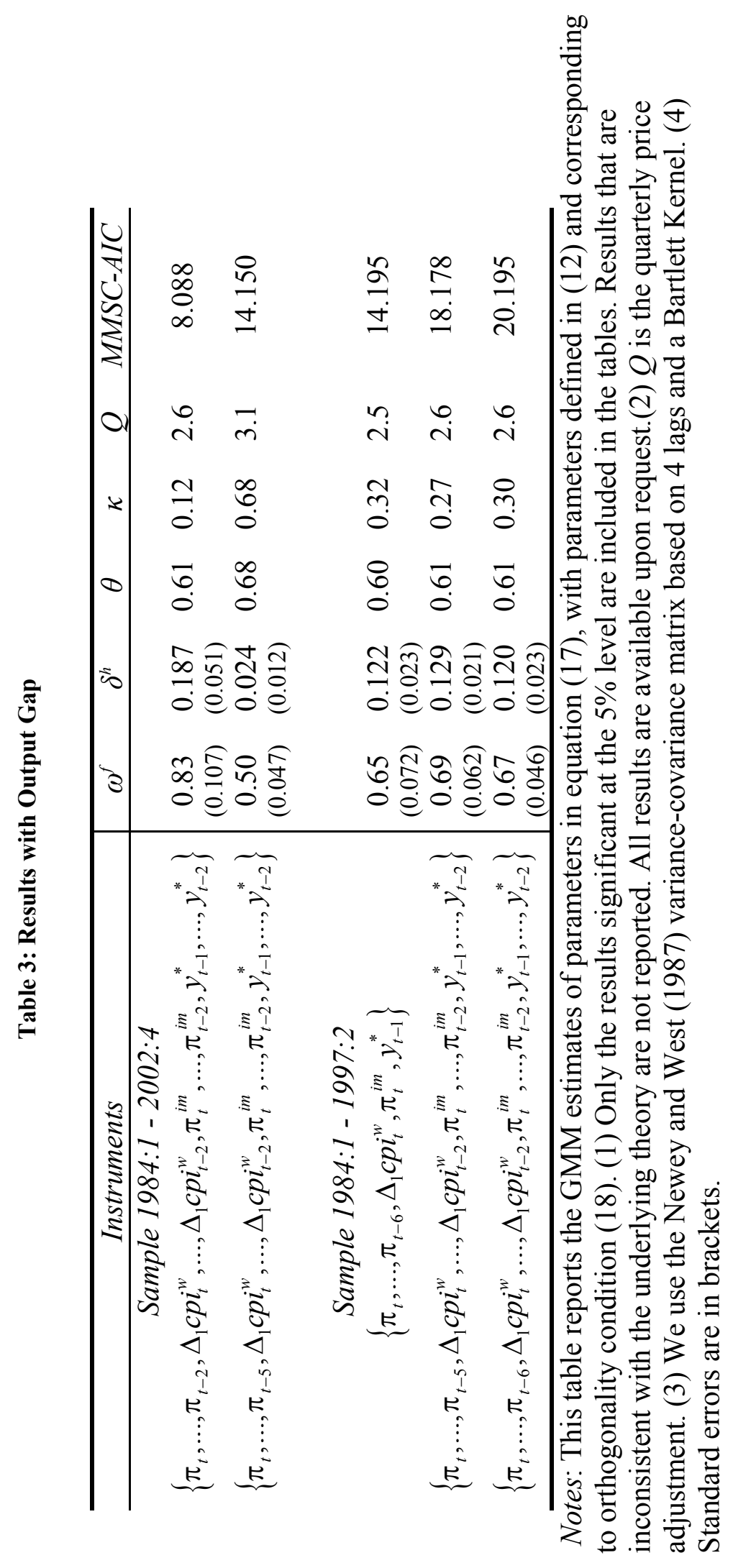




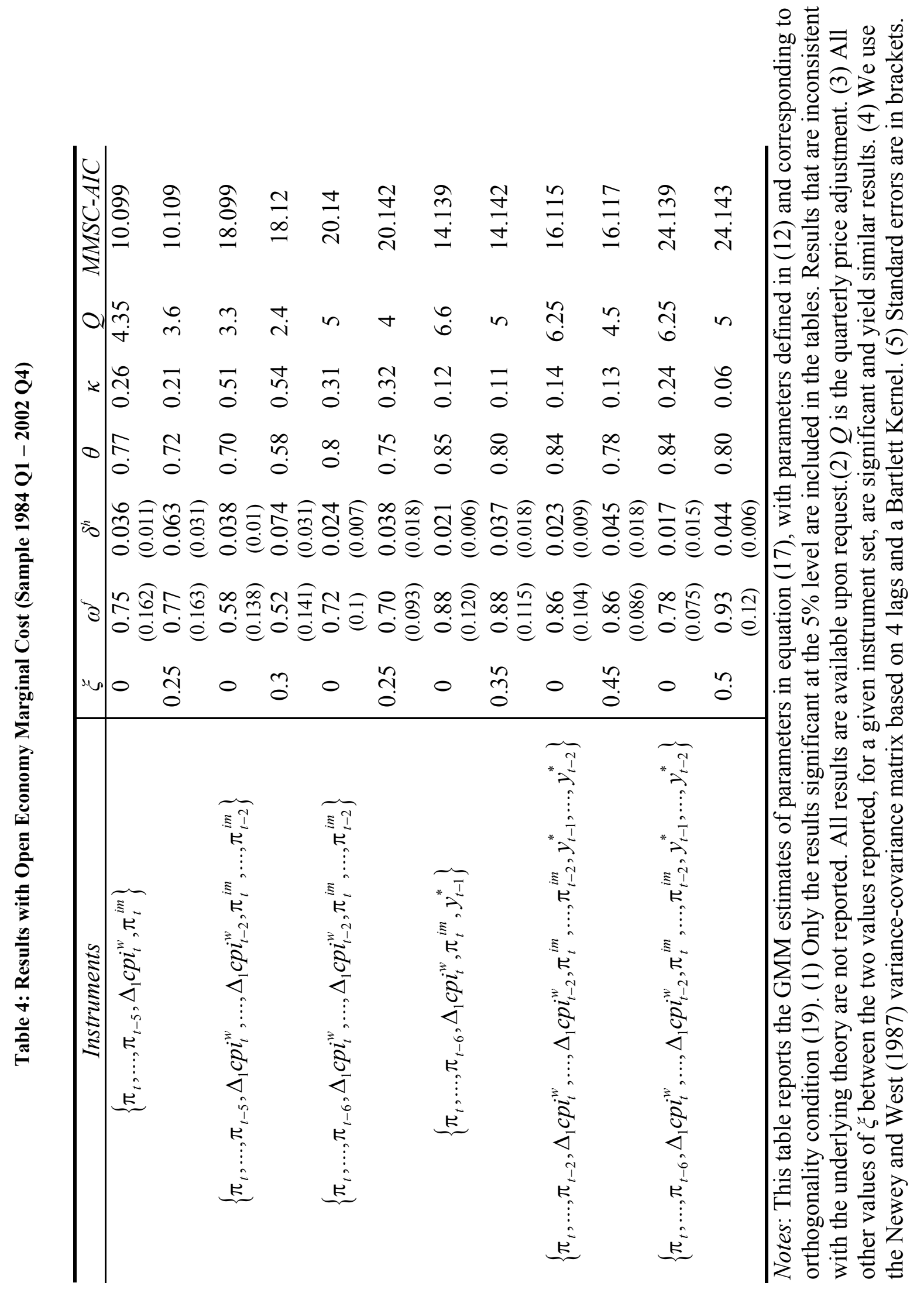




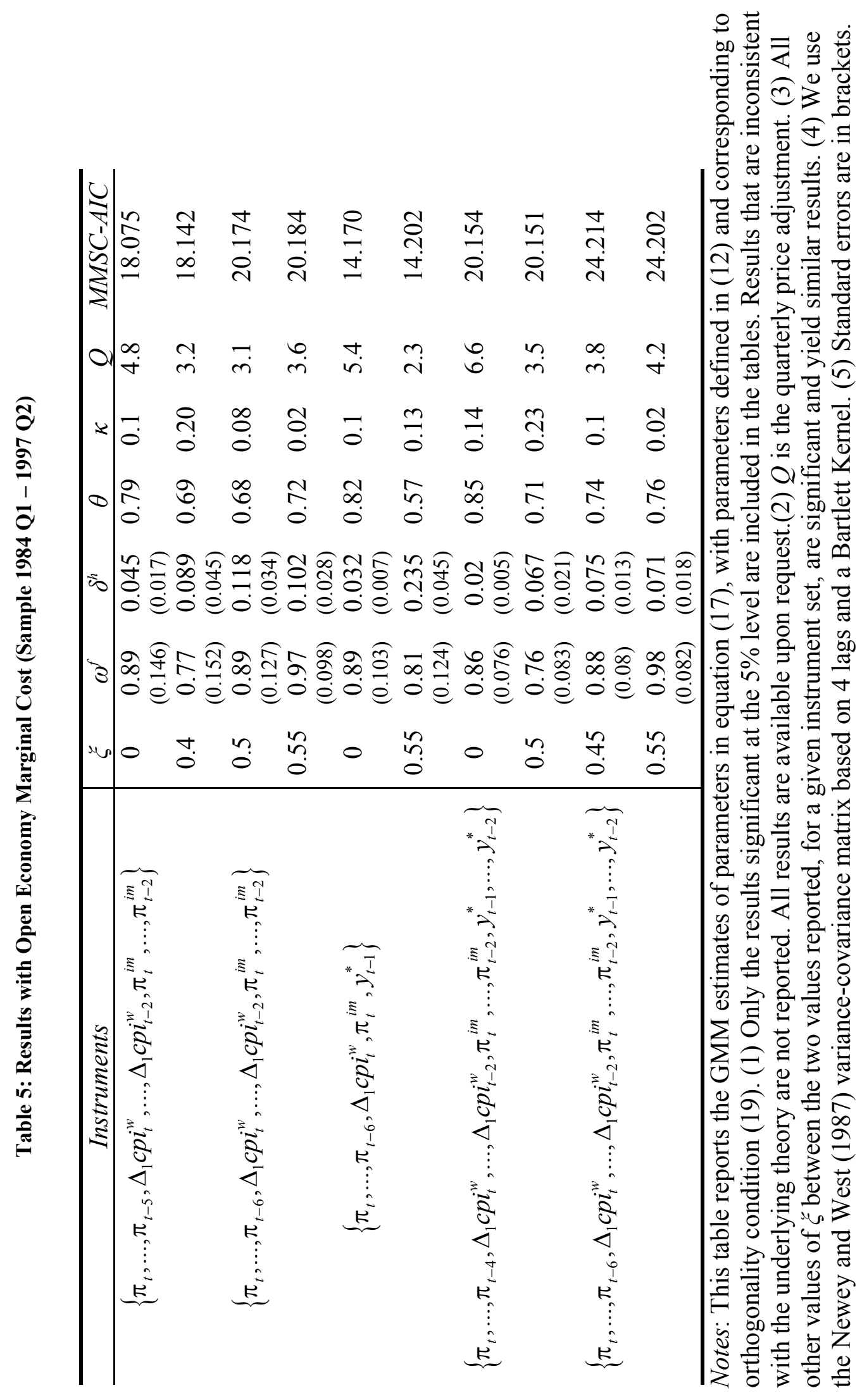

